\title{
Design and Implementation of Fitness Engineering System Based on Big Data Analysis
}

\author{
Yongjian Li \\ Jiangxi Science \&Technology Normal University, Jiangxi Nanchang, 330013, China \\ hustlu@163.com
} Keywords: Health System, Statue and characteristic, Community Residents, Public health, National
fitness engineering

\begin{abstract}
In view of the perspective of public service, the paper analyzed its function and meaning in sports development, explained the current supply situation of public sports development in our country, raised and analyzed the reasons of the supply disparity of urban and rural public sports service, It emphasized the overall planning for urban and rural public sports service so as to find a way to cater to the harmonious development between urban and rural, which includes 7 measures: Prioritize the rural economy, Adjust the financial expenditure, Ensure the supply of public sports service with strong Material base, Accelerate the process of rural areas to small towns, Emphasize the rights of migrant workers, Strengthen the farmers' rights in social development.
\end{abstract}

\section{Introduction}

Building a well-off society is the goal for Chinese socio-economic development in the first 20 years of this century. The goal of well-off society includes many meanings. A well-off society is not only the period with highly developed economic and high living standards, but also a society can meet people's spiritual and cultural needs. Under the guide for building a well-off society in an all-round way, physical education will bear more social values. It not simply emphasizes the competition, the gold medal, but takes it as people's daily life and ways to improve their fiving standard and quality. Building a better nationwide fitness system assures the foals above [1].

Our society has successfully resolved the problem of shortage of basic consumer goods since 30 years of reform and opening-up. However, the contradictions between the rapid growth of basic public needs and the shortage of basic public goods, the deficiency of public service is becoming increasingly apparent, especially in rural areas. China's rural society is in a critical transformation period from survival to development society, Compared with the beginning of the reform, the pressure of survival is weakening while the development issue is increasing.

The lack of public goods and public services are not in place has become a serious constraint problem in the rural socio-economic development, which has to be solved urgently. Due to the causes of urban and rural conditions of natural endowed resource as well as social history and political reasons, there is also great difference in public sports service level between urban and rural areas 2005 Gansu national physical fitness test shows that the city residents' excellence rate is $13.7 \%$, and farmers' only $6.1 \%$ and the urban residents physical failure rate was $11 \%$, while the farmers' was $19 \%$. In 2006, present situation of the mass sports investigation data in China showed that "land area of $16.1 \%$ and $29.92 \%$ of the urban population with sports venues proportion of the nation's $78.8 \%$,while more than $70 \%$ land area of the population $83.8 \%$ rural areas only have $20.20 \%$ sports resources". As the long-term reality that is mass sports and the athletic sports in a non-balanced development in China. The lag of rural social economy and the government policy in the urban and rural public sports development oriented bias of urban and rural areas, which resulting in obvious gaps between urban and rural public supply of sports goods. After the 2008 Olympic Games, President Hu pointed out that that our country should forward from "sporting nation" to "sports power", which means that China will pay more attention to the development of mass sports. Farmers in China as the largest social groups, without their participation in sports will be incomplete, in the course towards to "sports power", leaving their sports development and prosperity and everything will be in vain. Therefore, we 
can say that the harmony of urban and rural public sports development has reached a critical juncture.

This is not only just the needs of the development of sports in China but also the needs of China's social development. It is the purpose of this paper, from the analysis of the cause for this difference between urban and rural public service in our country sports supply, seeking for the ways of narrowing the gap between the services provided in urban and rural areas so that the public sports can be developed more harmonious.

National Fitness Program compendium which promulgated and startup by the State Department and is an impartment measure to improve the people's constitution, and raise the quality of nation. Citizen is of an important component of society population, their fitness carry out condition direct impact on the status of the implementation of this process and quality [2]. Center pointed we should accelerate the development of rural Cultural Educational Undertaking established in the suggestion of making "12th Five-Year" programming, which is further definitude the development role that country play in the socio-economic and cultural development. In building a well-off society and the building of a harmonious society in the national fitness program be implemented smoothly and progressively implemented, the key is the rural areas, are citizen. Without the development of national fitness engineering, China's social sports never achieve modernization, and it will never be able to achieve real meaning of the "National Fitness" purposes [3-4].

\section{The Main Problems of the Public Sports Supply Service in Urban and Rural Areas}

There are many problems in China's current public sports service supply in urban and rural, mainly in the following aspects: First, China's delivery mechanism of public sports service in urban and rural is not balanced. Government is the main provider of our public sports service product, the way of the supply is planned. Essentially, the supply of public sports service are pursuit for the national basic balance, but in fact from eastern Midwest to area (county) streets, the imbalance between regions is quite serious. The government's leading system for the supplies of whole society public sports service product is divided into fragments. In the city, the main supplier of public sports service has gradually from the country single supply to multiple ways, urban residents' physical activity supplied by the provincial and municipal sports bureau, trade unions, neighborhood committees, and sports clubs and sports associations at all levels [5]. Compared with the urban, the rural public service supply is still more single, which generally provided by local governments. Because of the assessment of local government officials are mostly concentrated in regional economic development level, which makes it tend to ignore the supply of public sports service. Many of the policy of mass sports reach rural areas would become "verbal policy", that is only hp expression level, lack of practical and feasible measures to protect it, which greatly restricts the concrete implementation of the government-led products and services of public sports supply [6].

Social sports instructors as one of the public service of important sports "soft facilities" equally has a huge difference between urban and rural areas Related material shows: in the current $10 \%$ social sports instructors in town, $90 \%$ in rural areas and there are only 18000 social sports instructors in rural areas which has a population of more than nine hundred million, an average of 50000 population have a social sports instructor.

\section{The Reasons for the Gap Generated of China's Urban and Rural Public Sports Service}

Since the early days of the implementation of our industry-leading non-equilibrium model of development, the implementation of "industry to subsidize agriculture," emphasize urban neglect of rural" ,to give priority to the development of urban development of tilt-based strategies and policies, long-term national policy to the urban bias, such as dual pricing system and the "scissors"

Although this kind of development mode greatly promote the industrialization, the urbanization process, but also formed a dual integral situation, whether in the national income or interest distribution pattern, the rural population all without exception, far behind the urban population. At present, the urbanization of our country are about $40 \%$, according to the nominal income to calculate, between urban and rural areas is about 3.2:1, which does not include actual enjoy services and welfare. 
If all the included_all-round calculation of income difference between urban and rural areas, is about 5-6:1 now. It can be said that the largest disharmonious in China is urban and rural areas. Therefore, the urban-rural dual economic structure is the fundamental reasons to differences in urban and rural public services

Unit system is an important feature of our social structure it is also a unique social phenomenon in China's modern cities. The unit sports under the planned economy of China's mass sports is the main part or mainstream, people used to call it "the staff sports". After the reform and opening, as China's economic system and economic structure has undergone significant changes, although the pattern of mass sports in China has had major changes, the "unit sports" is still an indispensable form of organization and basic form. Many institutions and enterprises have set up a staff sports clubs or sports room, mining and enterprises, which in good conditions, also have outdoor sports activities. Some foreign investors or joint venture with their own economic strength, lease the stadium near the work site to have the regular employee Games. However, farmers as a social group is not rely on work unit; they cannot enjoy the social welfare Thus, the unit sports have laid a foundation for the city's sports rapid development, but it also results further distance between urban and rural public sports services directly.

According to the theory of public goods, public finance theory, the supply of public goods should be divided responsibilities at all levels of government in accordance with powers and financial authority consistent with the principles of rational. The pure public goods or the benefit of the public goods should be supplied by the central government, the quasi-public goods or the parts benefit of public goods by local officials. This multilevel public service requirements the central and local government to bear different responsibilities in accordance with the size of public services outside, different grass-roots level of government to participate in public service supply. But in practice, many routine powers, which attribute to central or provincial government clearly has dislocated, they tend to deliver the responsibility to the grass-roots government. The financial power of grass-roots government is too focused on the central government, the freely raising financial resources was very limited since the agricultural tax and other rural tax reforms. This resulted in financial insufficient in grass-roots financial resources.

The so-called street bureaucratic refers to the grassroots level, and also the government workers in the forefront, they are the government employees who contact with the citizens directly. The supply of rural public sports service is often implemented by them because of these officials had immediate policy that will use their discretion to explain the instructions to make a localized of higher levels of government regulatory policies and documents, progressively put them into single multi-objective assessments of efficiency target Therefore, even higher levels of government develop a better public sports for rural development policies and regulations, which will be changed in their hand. Because sports administration often consider athletic sports work as an important criteria of assessment, form a non-competitive sports will select the next product in the over-supply, the real benefit of other farmers in the supply of public sports service is not satisfactory which form a competitive sports products in an unwanted choice of supply while other benefit to the farmers' public sports service project supply is not satisfactory. And some grassroots cadres like make achievements engineering, "face project". For example, some of the poorer rural areas build big luxurious facilities and club stadium, and these venues are closed in daily life, not open for farmers, just open for the higher-level visits patrol reviewing. This grass-roots government's higher satisfaction based on performance evaluation system largely inhibited the rural public services, and the effective supply of sports, so that for the farmers, many public sports polices are useless.

China's rural public service supply use "top-down" decision-making mechanism mainly, the public sports service supply largely depends on the preferences and interests and performance of government officials. As the cultural level and the asymmetry of information, the farmers are completely excluded in the decision of public sports service supply outside who cannot reflect their own needs accurate and timely In addition, as farmers, compared with the various social strata in the city, their degree of organization is relatively low, such as urban workers have trade unions, neighborhood committees, the street agency etc, these societies have played important roles in public 
sports products supply. For example, the Trade Union Law, Article 27 states: union workers should be organized to have recreational and sports activities. This form of law defined the responsibilities of union sports. Nowadays the new residential areas are equipped with fitness and entertainment facilities, the residential property management department also have been established the community sports department successively, organized full-time some activities regularly that enriched the residents' amateur cultural life and developed the community sports. However, the farmers, the largely total population in our country, are difficult to find a similar organization to express their wishes, interests and needs. Because the farmers are lack of the right to speak in this regard, some grass-roots cadres carry out bureaucratic style, performance projects and most farmers chose to turn a blind eye to the strange phenomenon.

China's rural public sports service needs a large scale requirement, they can't meet the goal if only rely on government financial investment, especially after the reform of agricultural tax, the grassroots government financial situation is worse. Therefore, to improve the rural investment of public sports service mechanism, establish multi-agent supply system, and use the market and NGOs to participate in the supply of rural public sports services have far-reaching meaning Such as mass sports that are huge supply of rural public sporting goods, the coordination mechanisms should be established; the cost should be shared reasonable by central government and local government. The central government provides facilities and equipments while the local government is responsible for supervision and repairs. For certain commercial quasi-public goods, such as rural clubs, the elderly exercise room and other grass-roots sports organizations, should mobilize and play the enthusiasm of all sectors of society, founded a separate or joint venture with the sports department. Under the property rights, according to the principle of "the investor get the profits, the introductory get the charge", through the preferential policies, introduce private funds and foreign investment to the rural public sports product supply

\section{Conclusions}

Sports health promotion with improvement of people's health condition for different purpose, in sports intervention as the means, the improvement of people's sports life style; To urge people to form healthy sports consciousness; The perfect sports environment, improve the quality of life of the process. Through the creation of the city health can achieve the above objectives. Through the health of the city can create perfect sports health promotion system, it is a can provide people with physical health services and to improve sports health promoting environmental conditions, satisfy people can the science fitness requirements, improve the quality of people's life and health level of service and security system.

\section{References}

[1] P. Klasnja and W. Pratt, Methodological Review: Healthcare in the Pocket: Mapping the Space of Mobile-Phone Health Interventions. Journal of Biomedical Informatics, Vol. 45, No. 1, 2012, pp. 184-198.

[2] Peihxin. Research on diversified national health services system of Well-off society. Beijing: Beijing Sport University Press, 2006:73

[2] China Statistical Yearbook 2006. Beijing: China Statistics Press, 2006.

[3] lvshuting,hudepei. Sociology of Sport. Beijing: People's sports press, 2007.

[4] Tianyu Pu. Research on mass sports of china. Beijing: People's sports press, 2004.

[5] Xiaolin Peng. Study on the equalization of public sports services. Sports culture guide, 2008.

[6] Weimin Zheng. Perfect the union sports work and build a harmonious society. Trade Union Forum, 2008. 